\title{
Trichoderma harzianum Enhances Antioxidant Defense of Tomato Seedlings and Resistance to Water Deficit
}

\author{
Fatemeh Mastouri, Thomas Björkman, and Gary E. Harman \\ Department of Horticulture, New York State Agricultural Experiment Station, Cornell University, 630 West North Street, \\ Geneva, New York 14456, U.S.A.
}

Submitted 21 September 2011. Accepted 9 April 2012.

Some plant-symbiotic strains of the genus Trichoderma colonize roots and induce profound changes in plant gene expression that lead to enhanced growth, especially under biotic and abiotic stresses. In this study, we tested the hypothesis that one of the protective mechanisms enhanced by $T$. harzianum T22 colonization is the antioxidant defense mechanism. Having established that strain T22 modulates the expression of the genes encoding antioxidant enzymes, the status of antioxidant defense of tomato seedlings in response to colonization by $\mathrm{T} 22$ and water deficit was investigated. Total ascorbate or glutathione levels were not affected by either stimuli, but under water deficit, antioxidant pools became more oxidized (lower ratios of reduced to oxidized forms), whereas colonized plants maintained redox state as high as or higher than unstressed and untreated plants. The enhanced redox state of colonized plants could be explained by their higher activity of ascorbate and glutathione-recycling enzymes, higher activity of superoxide dismutase, catalase, and ascorbate peroxidase, in both root and shoot throughout the experiment. Similar enzymes were induced in uncolonized plants in response to water-deficit stress but to a lower extent when compared with colonized plants. This orchestrated enhancement in activity of reactive oxygen species (ROS)scavenging pathways in colonized plants in response to stress supports the hypothesis that enhanced resistance of colonized plants to water deficit is at least partly due to higher capacity to scavenge ROS and recycle oxidized ascorbate and glutathione, a mechanism that is expected to enhance tolerance to abiotic and biotic stresses.

Fungi in the genus Trichoderma and products based on efficient strains thereof are commonly used to enhance yield and reduce plant diseases (Harman 2011; Harman et al. 2004a). Among the beneficial outcomes of Trichoderma-plant interaction, enhanced resistance to abiotic stresses (Bae et al. 2009; Mastouri and Harman 2009; Mastouri et al. 2010; Yildirim et al. 2006) has lately attracted more attention, as understanding the nature of this phenomenon may provide potentially useful tools to enhance crop production.

Colonization of host roots with Trichoderma strains enhances whole-plant tolerance to biotic and abiotic stresses (Bjorkman et al. 1998; Shoresh et al. 2010). Such enhanced tolerance to biotic and abiotic stress may, in part, be due to en-

Corresponding author: F. Mastouri; E-mail: fm79@cornell.edu

* The $\boldsymbol{e}$-Xtra logo stands for "electronic extra" and indicates that Figure 1 appears in color online. hanced root growth and nutritional status of plants (Harman 2000; Harman et al. 2004a) as well as induced systemic resistance to diseases (Harman et al. 2004b). However, differences in root growth (Harman et al. 2004a) or enhanced nutritional status of plants (Yildrim et al. 2006) do not fully explain our recent observation that $T$. harzianum $\mathrm{T} 22$ improves tolerance to a wide range of stresses, including water deficit, salinity, suboptimal temperatures, reduced seed quality (Mastouri et al. 2010), or excess light (Shoresh et al. 2010). An increase in damaging levels of reactive oxygen species (ROS) is a common factor in all these stresses (Apel and Hirt 2004; Mittler 2002). The ability of T22-colonized plants to tolerate these varied sources of stress suggested that these changes might have been at least partially mediated by enhanced redox buffering capacity of the colonized plants. Under water deficit, lipid peroxide content of colonized seedlings was lower than in the control seedlings (Mastouri et al. 2010). Lipid peroxidation is commonly associated with oxidative damage (SanchezRodriguez et al. 2010) when the level of ROS exceeds the capacity of the antioxidant defense system (Mittler 2002; Miller et al. 2007; Rizhsky et al. 2004). While changes in ROS level may act as a signal to activate a host of defense mechanisms, continued production of high levels of ROS under ongoing stress causes damage to plants (Mittler 2002). Defense against damaging levels of ROS includes enzymatic and nonenzymatic components. Superoxide dismutases (SOD) (EC 1.15.1.1), ascorbate peroxidases (EC 1.11.1.11), and catalases (CAT) (EC 1.11.1.6) act as main enzymatic scavengers of superoxide $\left(\mathrm{O}_{2}^{-}\right)$and hydrogen peroxide $\left(\mathrm{H}_{2} \mathrm{O}_{2}\right)$. Glutathione $(\mathrm{GSH})$ and ascorbic acid (ASA) are the major nonenzymatic antioxidants that, among other vital functions, maintain cellular redox homeostasis (Noctor and Foyer 1998). Keeping ASA and GSH in reduced form is critical for redox homeostasis and cellular vitality (de Pinto et al. 1999), and the activity of the enzymes that regenerate these molecules is correlated with resistance to abiotic stresses (Baltruschat et al. 2008; Mittova et al. 2000a and b; Smirnoff 1993). These enzymes include glutathione reductase (GR) (EC 1.8.1.7), which regenerates oxidized GSH (glutathione disulfide [GSSG]), and monodehydroascorbate reductase (MDHAR) (EC 1.6.5.4) and dehydroascorbate reductase (DHAR) (EC 1.8.5.1), which regenerate ASA from monodehydroacrobate (MDHA) and dehydroascorbate (DHA). A simplified diagram of plant antioxidant defense has been published by Mittler (2002).

The main goal of this study was to investigate the ability of $T$. harzianum T22 to potentiate antioxidant defense in tomato seedlings. Germination percentage or the ability of treated or untreated seeds to establish normal seedlings within 14 days was compared under water-deficit stress and exposure to methyl viologen (MV), conditions known to enhance ROS production. 
Growth and chlorophyll concentration of colonized and uncolonized seedlings under water deficit was compared. To better elucidate the role of strain T22 in regulation of antioxidant defense, the relative expression of genes encoding antioxidant enzymes in tomato root and shoot was studied. T22 colonizes only roots, so changes in shoots are due to systemic effect on regulation of gene expression. The activity of enzymatic components of antioxidant defense of colonized plants in response to water-deficit stress was compared with uncolonized plants. In addition, the redox state of ascorbate and glutathione and the activity of enzymes of the ascorbate-glutathione cycle in response to T22 and water deficit was investigated to determine whether colonized seedlings were better capable of maintaining redox balance under stress and if this was due to i) increased concentration of either or both the antioxidant molecules glutathione and ascorbate, ii) due to the improved capacity of colonized plants to regenerate these antioxidant molecules, or iii) whether both mechanisms happened concurrently.

\section{RESULTS}

\section{T22 colonization reduces oxidative inhibition of seed germination and seedling growth caused by MV and water deficit.}

T22 treatment of tomato seeds enhanced germination percentage under water deficit or in the presence of MV (Table 1; Fig. 1). Water deficits sufficient to reduce growth of uncolonized seedlings had a much smaller effect on colonized seedlings. T22 colonization enhanced both fresh and dry weight of tomato roots and shoots under water deficit (Table 2). Likewise, the chlorophyll content of leaves, as expressed in SPAD units, was reduced by water deficit, but that effect was, in large part, overcome in the presence of T22 (Table 2).

\section{T22 affects expression of genes encoding}

\section{antioxidant enzymes, especially in systemic tissue.}

Strain T22 colonizes roots and remains limited to the cortex and outer layers of the root epidermis (Yedidia et al. 1999) of host plants, but it modulates gene expression in both shoots and roots. In this experiment, T22 colonization resulted in significantly higher expression of chloroplastic and cytosolic
$M D H A R, D H A R$, and $G R$, which are ASA and GSH recycling enzymes, as well as cytosolic $A P X$ (Fig. 2A) indicating the possibility of upregulation of the ascorbate-glutathione cycle, especially in cytosol of shoots of colonized plants. SOD expression increased in response to colonization by T22, with a large increase in the relative expression of chloroplastic $F-S O D_{p}$ and $C Z-S O D_{p}$ but not cytosolic $S O D_{c}$ (Fig. 2A). T22 colonization did not affect the expression of the two CAT genes studied (Fig. 2A). The response of antioxidant systems in roots was much more limited. In roots of colonized seedlings, only a cytosolic ascorbate peroxidase, $\mathrm{APX}_{\mathrm{c}}$, was upregulated relative to uncolonized roots (Fig. 2B).

\section{T22-colonized seedlings maintain} ascorbate and glutathione in the reduced form.

Pool size (reduced + oxidized) and redox state (reduced/oxidized) of ascorbic acid and glutathione in shoots and roots of tomato seedlings were analyzed 3 and 10 days after $50 \%$ of the

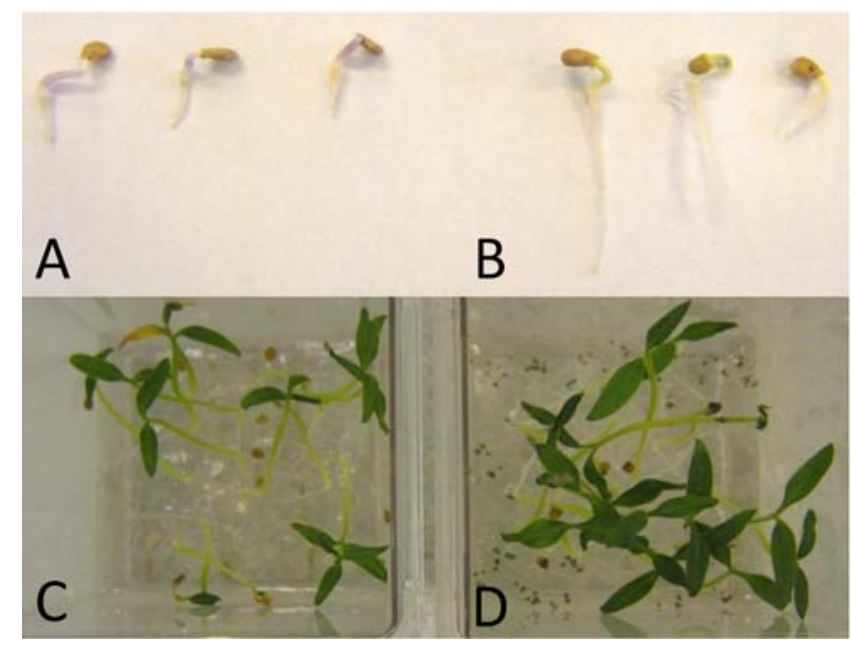

Fig. 1. Effect of Trichoderma harzianum T22 treatment and methyl viologen or water deficit on growth of tomato seedlings. A, $20 \mu \mathrm{M}$ methyl viologen; B, 20 $\mu \mathrm{M}$ methyl viologen $+\mathrm{T} 22 ; \mathbf{C}, 13.8 \%$ polyethylene glycol (PEG); and D, T22 + 13.8\% PEG.

Table 1. Effects of water deficit, methyl viologen (MV), and T22 on germination of tomato

\begin{tabular}{|c|c|c|c|c|c|}
\hline \multirow[b]{2}{*}{ Stress } & \multicolumn{2}{|c|}{ Germination $(\%)^{w}$} & \multicolumn{3}{|c|}{ Statistical significance of effect ${ }^{x}$} \\
\hline & $-\mathbf{T 2 2}$ & $+\mathbf{T} 22$ & $\mathbf{T 2 2}$ & Stress & Interaction \\
\hline Control & $90.1 \pm 4.9$ & $89.9 \pm 3.2$ & n.s. & - & - \\
\hline$-0.2 \mathrm{MP}^{\mathrm{y}}$ & $75.1 \pm 4.3$ & $88.2 \pm 3.6$ & $*$ & $*$ & $*$ \\
\hline$-0.4 \mathrm{MPa}^{\mathrm{z}}$ & $48.3 \pm 5.9$ & $80.3 \pm 3.8$ & $*$ & $*$ & $* *$ \\
\hline $\mathrm{MV}(20 \mu \mathrm{M})$ & $72.3 \pm 4.4$ & $81.9 \pm 5.7$ & n.s. & $* *$ & $* *$ \\
\hline
\end{tabular}

${ }^{\mathrm{w}}$ Germination percentage was measured 14 days after the start of imbibition.

x Symbols: n.s., *, and ** indicate nonsignificant effect or significant at $\alpha=0.05$ or 0.01 , respectively.

y Seedlings germinated in Murashige and Skoog (MS) medium containing 13.8\% polyethylene glycol (PEG) 8000.

${ }^{\mathrm{z}}$ Seedlings germinated in MS medium containing $19.6 \%$ PEG 8000.

Table 2. Effect of Trichoderma harzianum and water deficit on biomass and chlorophyll content of tomato seedlings ${ }^{\mathrm{w}}$

\begin{tabular}{|c|c|c|c|c|c|c|}
\hline Seedling $^{x}$ & Control & $-0.2 \mathrm{MPa}$ & $-0.4 \mathrm{MPa}$ & +T22 & $-0.2 \mathrm{MPa}+\mathrm{T} 22$ & $-0.4 \mathrm{MPa}+\mathrm{T} 22$ \\
\hline Shoot FW & $27.1 \pm 2.1 \mathrm{a}$ & $22.4 \pm 2.3 b$ & $11.3 \pm 2.4 \mathrm{c}$ & $25.7 \pm 1.9 \mathrm{ab}$ & $26.3+2.0 \mathrm{ab}$ & $23.7 \pm 1.8 \mathrm{ab}$ \\
\hline Shoot DW & $2.0 \pm 0.1 \mathrm{a}$ & $1.6 \pm 0.1 \mathrm{~b}$ & $1.4 \pm 0.2 b$ & $1.9 \pm 0.1 \mathrm{a}$ & $1.8 \pm 0.1 \mathrm{ab}$ & $1.7 \pm 0.1 \mathrm{ab}$ \\
\hline Chlorophyll content $^{y}$ & $39.3 \pm 1.2 \mathrm{a}$ & $33.6 \pm 1.5 \mathrm{~b}$ & $31.2 \pm 2.1 \mathrm{~b}$ & $39.6 \pm 1.3 \mathrm{a}$ & $38.7 \pm 2.1 \mathrm{ab}$ & $37.3 \pm 1.9 \mathrm{ab}$ \\
\hline Root $\mathrm{FW}^{\mathrm{z}}$ & $9.2 \pm 0.2 \mathrm{a}$ & $7.4 \pm 0.3 \mathrm{~d}$ & $5.6 \pm 0.3 \mathrm{e}$ & $9.4 \pm 0.3 \mathrm{a}$ & $8.5 \pm 0.2 b$ & $8.2 \pm 0.2 \mathrm{c}$ \\
\hline Root DW ${ }^{z}$ & $0.85 \pm 0.03 \mathrm{a}$ & $0.60 \pm 0.06 b c$ & $0.52 \pm 0.04 \mathrm{c}$ & $0.84 \pm 0.05 \mathrm{a}$ & $0.77 \pm 0.04 \mathrm{ab}$ & $0.73 \pm 0.04 b$ \\
\hline
\end{tabular}

wResults are means of five replications per treatment. Means followed by the same letter are not statistically different according to Tukey's multiple comparisons test $(P<0.05)$.

${ }^{\mathrm{x}}$ Fresh weight $(\mathrm{FW})$ and dry weight (DW) measured 21 days after the start of imbibitions for all normal seedlings in each treatment.

${ }^{y}$ Chlorophyll content of a fully developed leaf of three normal seedlings measured 21 days after the start of imbibitions.

${ }^{\mathrm{z}}$ Root dry weight is average of dry weight of all roots pooled and dried together. 
seeds germinated. T22 and stress did not affect total pool size of glutathione or ascorbate (Figs. 3 and 4) but did affect the ratio of reduced to oxidized forms of the molecules (hereafter the ratios are referred to as ASA:DHA and GSH:GSSG for
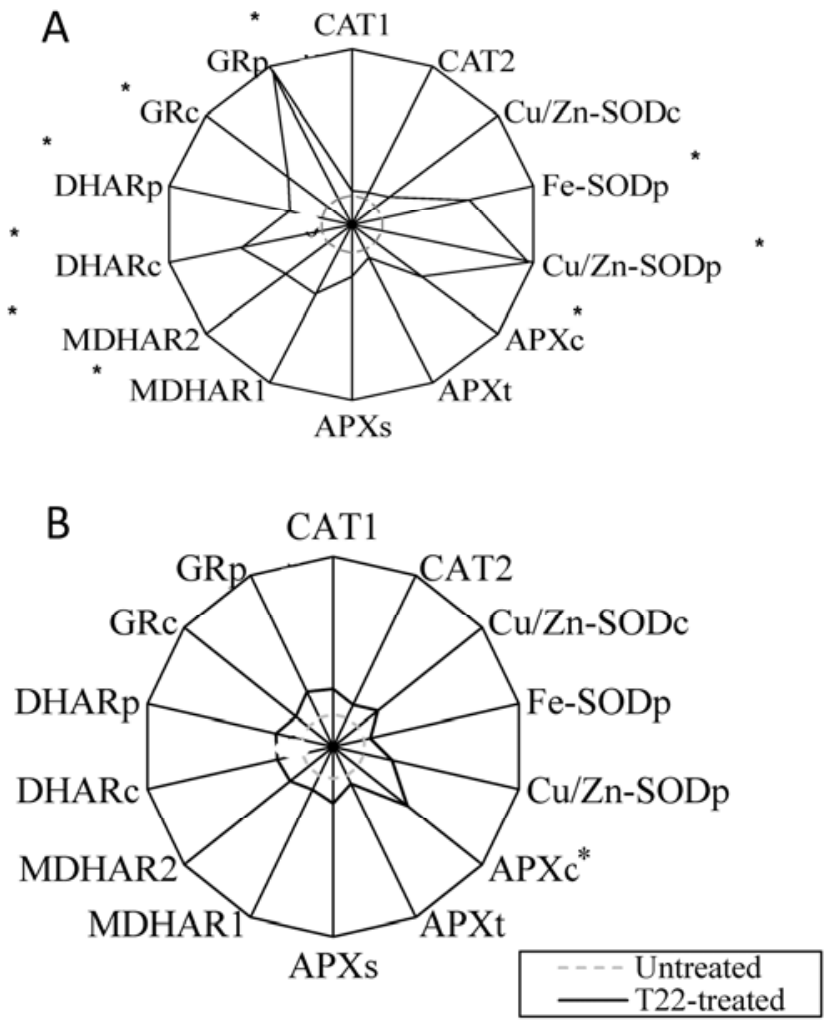

Fig. 2. Relative expression of genes encoding antioxidant enzymes in $\mathbf{A}$, shoots and B, roots of Trichoderma harzianum T22-treated seedlings normalized to those of control shoots and roots (inner circle). The outer circle shows $6 \times$ expression. Asterisks indicate significant gene expression $(\geq 2 \times)$.
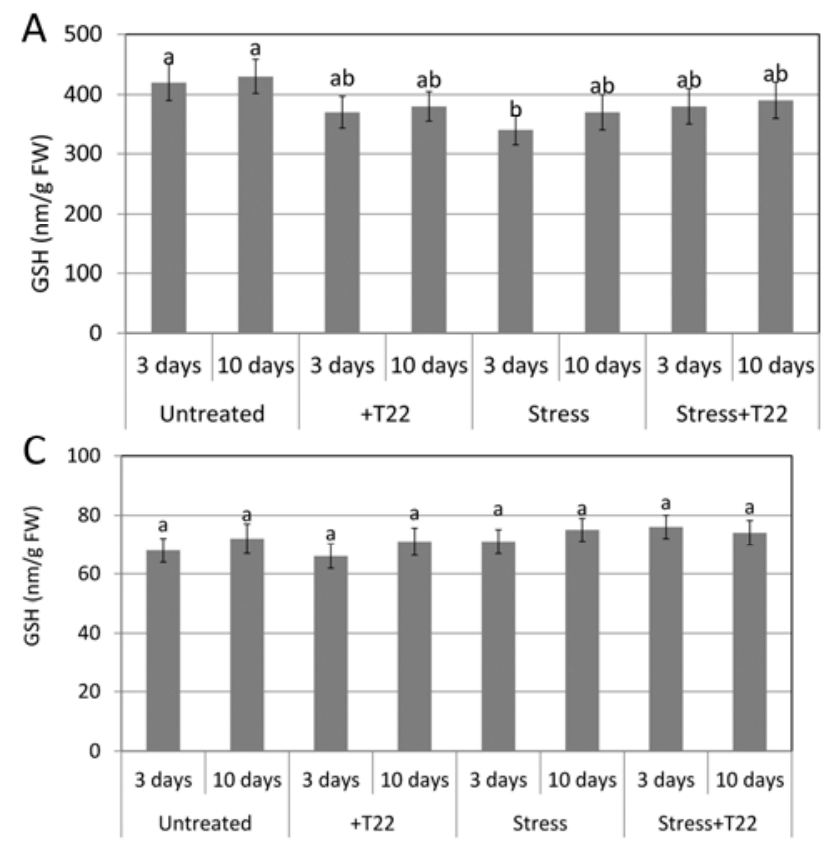

ascorbate and glutathione, respectively). Water stress reduced the ratio of GSH:GSSG only in the first measurement in roots (Fig. 3B and D). In the presence of T22, these ratios tended to be higher especially under stress (Fig. 3B and C). Water-deficit stress significantly reduced the ratio of ASA:DHA to about $20 \%$ of the control levels, but in colonized plants, this ratio was similar to that of the untreated control and was significantly higher than with stress alone (Fig. 4A and B).

\section{T22 colonization and water deficit upregulate the ascorbate-glutathione cycle, CAT, and SOD.}

Given the importance of the ascorbate-glutathione cycle in maintaining cellular redox, ROS-scavenging, and signal transduction (Mittler 2002), the activity of these enzymes as affected by water deficit, T22 colonization, and time of sampling was studied. Samples were taken 3 and 10 days after $50 \%$ of seedlings had emerged. Enzyme activities were normalized to those of untreated seedlings 3 days after $50 \%$ of seeds germinated, which respectively were $230.1,204.3,35.9$, and $29.6 \mathrm{nmol}$ protein per minute per milligram, respectively, for APX, MDHAR, DHAR, and GR in shoots. Respective enzyme activities in roots of untreated seedlings 3 days after $50 \%$ of seeds germinated were $122.2,109.2$, 28.6, and $20.1 \mathrm{nmol}$ protein per minute per milligram. As observed by the results of gene expression, the ascorbate-glutathione cycle was upregulated by T22 colonization. The activity of APX was enhanced by both water deficit and T22 colonization in shoots and roots and was increased over time (Fig. 5A and B). The activity of MDHAR was affected by water deficit and T22 colonization. Time of sampling did not affect MDHAR activity in shoots, but the MDHAR activity of untreated roots reduced over time under stress (Fig. 5A and B). DHAR enzyme activity increased in response to T22 but not stress. DHAR activity reduced over time in uncolonized seedlings but not in colonized seedlings (Fig. 5A and B). The activity of GR in shoots was enhanced by T22 colonization and water deficit (Fig. 5A), but in roots, only T22 by stress interaction significantly affected the GR activity (Fig. 5B).
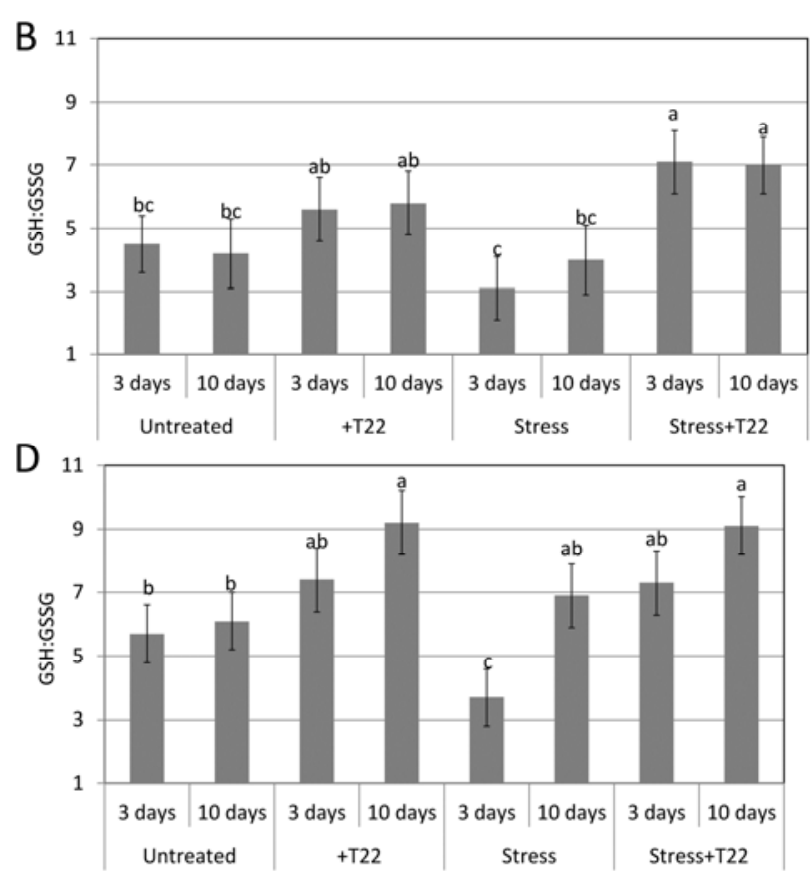

Fig. 3. Concentration and redox state of glutathione, respectively, in $\mathbf{A}$ and $\mathbf{B}$, tomato shoot and $\mathbf{C}$ and $\mathbf{D}$, root as affected by Trichoderma harzianum T22 colonization and water deficit 3 and 10 days after 50\% of seeds germinated. Each number is the average of three measurements of a pool of five shoots or roots per treatment. Each treatment was repeated in five replicates. Only means followed by different letters are statistically different, according to Tukey's multiple comparisons test $(P<0.05)$. 

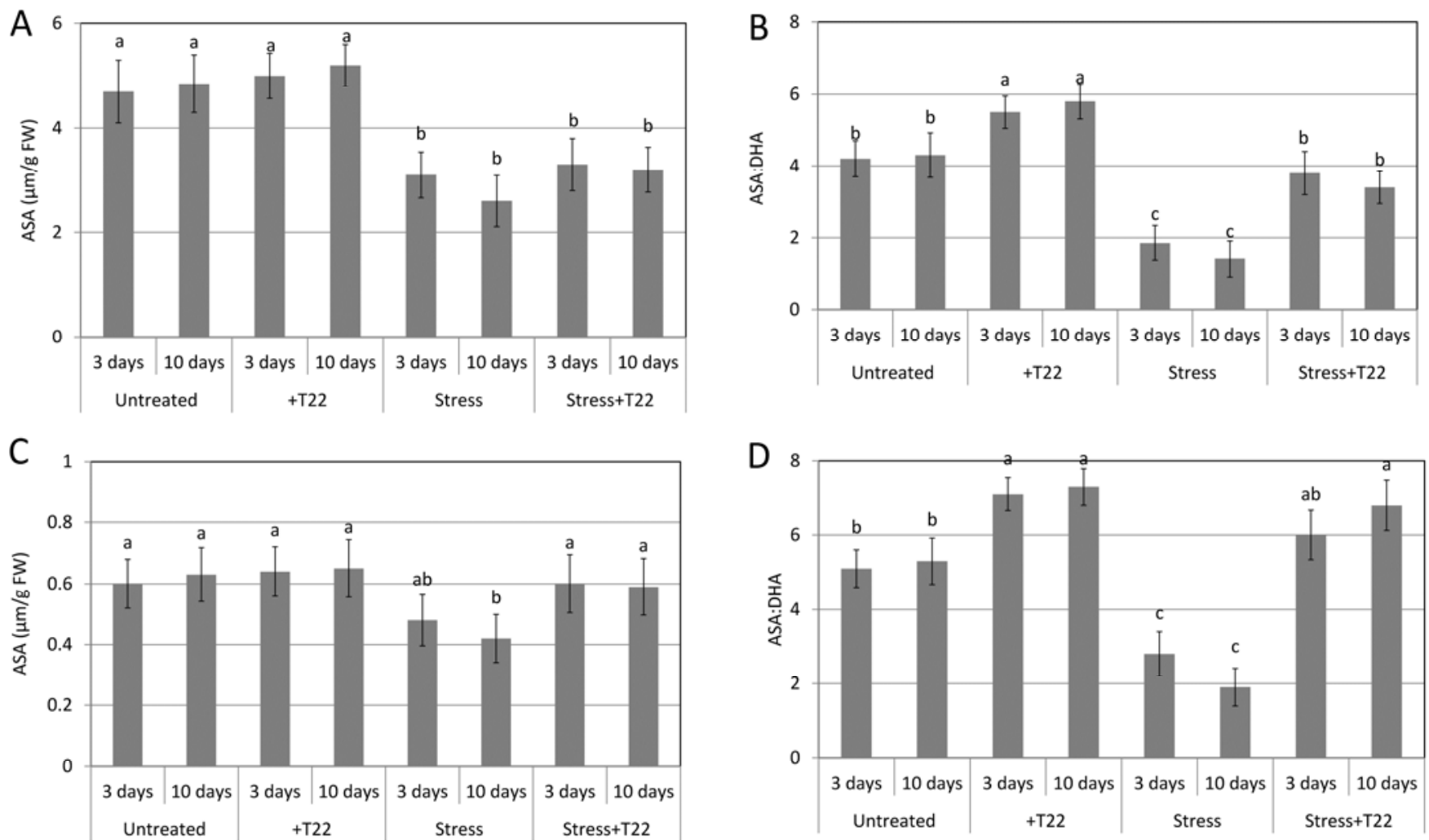

Fig. 4. Concentration and redox state of ascorbate in $\mathbf{A}$ and $\mathbf{B}$, tomato shoot and $\mathbf{C}$ and $\mathbf{D}$, root as affected by Trichoderma harzianum T22 colonization and water deficit 3 and 10 days after 50\% of seeds germinated. Each number is the average of three measurements of a pool of five shoots or roots per treatment. Each treatment was repeated in five replicates. Means followed by different letters are not statistically different according to Tukey's multiple comparisons test $(P<0.05)$
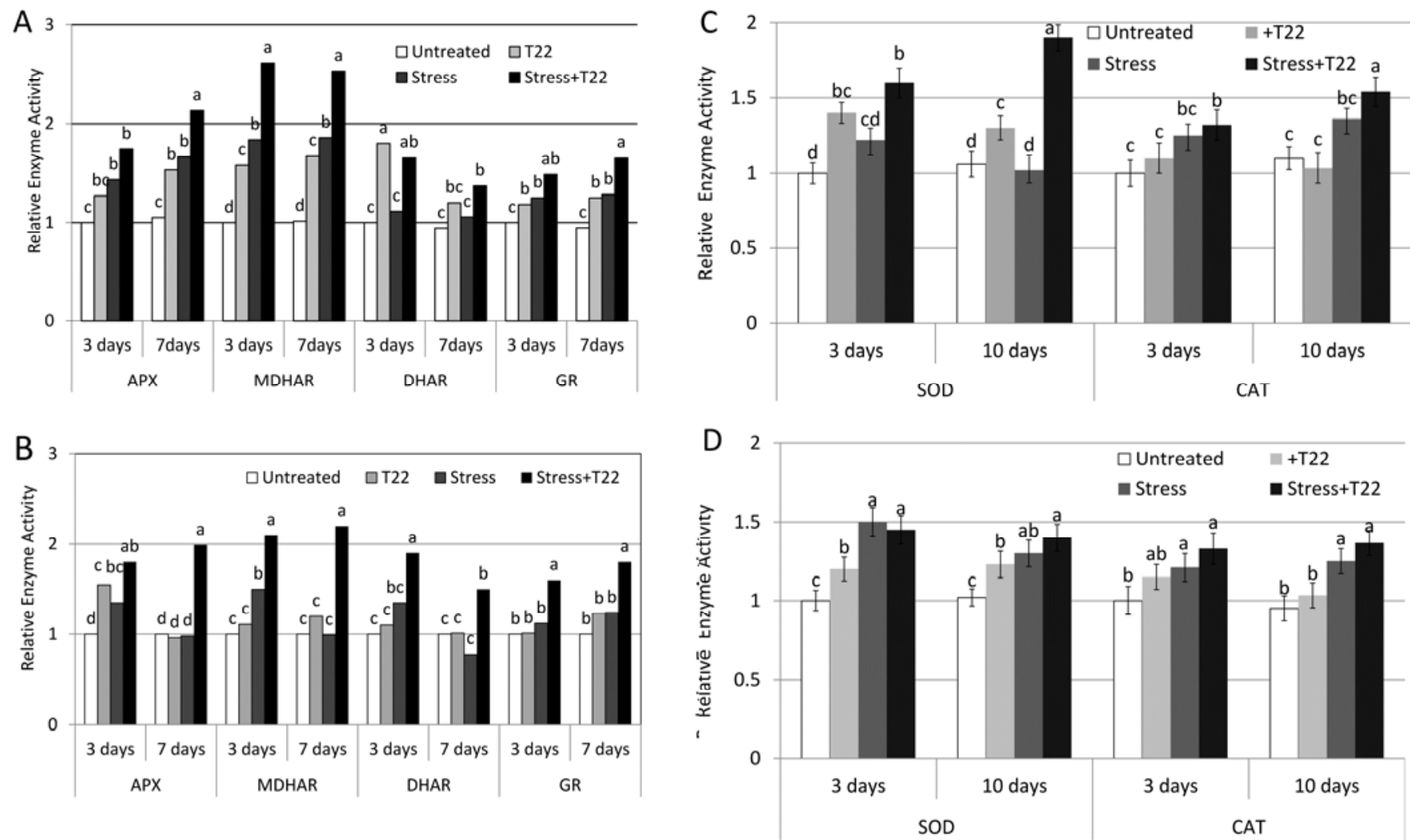

Fig. 5. Relative activity of enzymes of $\mathbf{A}$, ascorbate-glutathione cycle and ascorbate peroxidase in shoots and $\mathbf{B}$, in roots and $\mathbf{C}$, superoxide dismutases (SOD) and catalases (CAT) in shoots and D, in roots of tomato plants was affected by osmotic stress (addition of polyethylene glycol to media), Trichoderma harzianum T22, and time of sampling. Enzyme activities normalized to those of untreated seedlings 3 days after $50 \%$ of seeds germinated. Each number is the average of three measurements of a pool of five shoots or roots per treatment. Each treatment was repeated in five replicates. Only means followed by different letters are statistically different, according to Tukey's multiple comparisons test $(P<0.05)$. 
Activities of CAT and SOD were normalized to those of untreated seedlings 3 days after germination of $50 \%$ of seeds, respectively, $0.51 \mu \mathrm{mol}$ per gram of fresh weight $(\mathrm{FW})$ per minute and $5.31 \mathrm{U}$ per gram of $\mathrm{FW}$ for CAT and SOD in shoots and $0.43 \mu \mathrm{mol}$ per gram of FW per minute and $3.40 \mathrm{U}$ per gram of FW in roots. Under stress, SOD activity of shoots of uncolonized plants was initially induced but declined over time (Fig. 5C). Roots maintained relatively high SOD activity under stress, even though a decline in SOD activity of roots ofuncolonized plants was observed in later measurement (Fig. 5D). Both root and shoot SOD activity was induced by T22, especially under stress (5C and D).

Root and shoot CAT activity was enhanced in response to stress but not root colonization (Fig. 5C and D). However, the stress $\times$ T22 effect was significant, and under stress, root and shoot CAT activity of colonized plants was higher than uncolonized plants (Fig. 5C and D).

\section{DISCUSSION}

Trichoderma spp. colonize plant roots and establish symbiotic relationships with a wide range of host plants. As a consequence, plant growth and performance frequently is enhanced (Harman 2011; Harman et al. 2004b; Shoresh et al. 2010).

In this paper, we present several lines of evidence that root colonization by T22 enhances systems of ROS scavenging and redox maintenance. First, T22 colonization partially overcame the damage from MV. MV causes oxidative damage to photosynthetic machinery by increasing ROS production and accumulation (Asada 2000). Enhanced ROS-scavenging ability, especially mediated by SOD activity in chloroplasts, is linked to enhanced resistance to MV (Fujibe et al. 2004), and we demonstrate here that T22 induces SOD expression in chloroplasts and significantly upregulates whole-plant SOD activity.

Second, we demonstrate that redox maintenance systems are improved by T22. Reductive power for redox maintenance is stored in pools of ascorbate and glutathione. Under stress, T22 enhanced the redox state of both pools without increasing their total pool size (Figs. 3 and 4). The reduced forms of glutathione and ascorbate play a key role in defense and redox buffering, and low ratios of reduced to oxidized form of these molecules diminishes plant growth by blocking or delaying cell division and reducing protein synthesis (de Pinto et al. 1999). Further, oxidation of the ASA pool inactivates APX. Thylakoid-bound APX, whose inactivation leads to $\mathrm{H}_{2} \mathrm{O}_{2}$ and $\mathrm{O}_{2}^{-}$ accumulation in chloroplast and irreversible damage to photosynthetic machinery, is especially sensitive to low ASA availability (Asada 2000). Increasing glutathione content, on the contrary, does not increase growth or tolerance to abiotic stresses (Foyer et al. 1995; Xiang and Oliver 1998) or, in one case, even compromises growth due to oxidative damage (Creissen et al. 1999). The increase in the reduced form of these antioxidant molecules was accompanied by higher expression of genes expressing MDHAR, DHAR, and GR and their activities in colonized seedlings, especially under stress (Figs. 2 and 5A and B). The other components of antioxidant defense that help maintain redox balance of plant, namely ROSscavenging enzymes SOD, CAT, and APX, also showed elevated activity in colonized plants under stress. The activity of antioxidant enzymes was also induced in response to water deficit in uncolonized plants. However, the difference in the levels of their activity in colonized and uncolonized plants over time (Fig. 5) explains the ability of colonized plants to maintain a redox state similar to or higher than unstressed plants (Figs. 3 and 4).

This mechanism is one of several mechanisms that increase drought tolerance of crops provided by $\mathrm{T} 22$. Increased root growth, which is frequently observed in drought-tolerant plants (Harman 2000), may also contribute to avoidance of Trichoderma-colonized plants. However, such a mechanism cannot explain the tolerance to abiotic stresses explained in this study or our previous one (Mastouri et al. 2010). In our seed-germination study, effects were noted at or before radical protrusion from the seeds, and in this study, water stress was created osmotically by the addition of polyethylene glycol (PEG), so greater root growth was not involved in either case. However, this study demonstrates an additional mechanism by which Trichoderma spp. induce plant tolerance to water deficit and other abiotic stresses.

Root colonization resulted in a greater increase in the expression of antioxidant enzymes in shoots (systemic tissue) compared with roots. Differences in root and shoot gene expression in response to root colonization has been previously reported for Trichoderma harzianum (Shoresh and Harman 2008) and Piriformospora indica (Waller et al. 2005). Trichoderma spp. induce systemic changes in gene expression through a complex signal transduction network with methyl jasmonate (MeJA) playing the pivotal role (Shoresh et al. 2005). MeJA induces expression of genes encoding antioxidant enzymes, including GR. We found a CGTCA-motif, a MeJA-responsive element (Rouster et al. 1997), in a promoter of the majority of genes encoding antioxidant enzymes in Arabidopsis thaliana (data not shown), which suggests that MeJA may play a signaling role in the expression of genes encoding antioxidant enzymes as well.

The data in this paper advance the model that Trichoderma spp. improve the ability of plants to remove damaging ROS. The ability of seedlings to protect themselves from oxidative damage was accompanied by upregulation of genes for enzymes that reduce glutathione and ascorbate, an increase in the activity of those enzymes, as well as a shift in the redox state of glutathione and ascorbate pools toward the reduced state. Taken together, these data strongly support the concept that root colonization by T22 enhances abilities of plant to scavenge or remove damaging levels of ROS, presumably $\mathrm{O}_{2}^{-}$and $\mathrm{H}_{2} \mathrm{O}_{2}$. This ability appears to at least partially explain resistance of T22-colonized plants to water deficit, MV exposure, and other abiotic stresses.

\section{MATERIALS AND METHODS}

\section{Plant material and seed treatment.}

Trichoderma harzianum T-22 (American Type Culture Collection number 20847) was used as a seed inoculant for this study. This strain, produced by protoplast fusion, colonizes roots of diverse host plants (Sivan et al. 1991) causing systemic changes in host gene expression (Harman et al. 2004a; Shoresh and Harman 2008). Conidia of T22 coated in a cellulose powder and encapsulated with tapioca dextran (CrystalTex, Bridgewater, NJ, U.S.A.) were suspended in sterile ultrapure water. Seeds of tomato (Lycopersicum esculentum L.) cultivar Jubilee (Harris seeds, Rochester, NY, U.S.A.) were treated with $20 \mu \mathrm{l}$ of the conidial suspension per gram to deposit $2 \times 10^{7} \mathrm{CFU}$ per gram of seeds. Control seeds were treated with an equal amount of type I sterilized water.

Murashige and Skoog (MS) medium in $0.25 \%$ phytagel (Sigma-Aldrich, St. Louis) was used as germination and seedling growth media. For stress experiments, PEG 8000 (SigmaAldrich) was added after autoclaving media at 13.8 and $19.6 \%$ final concentrations $(-0.2$ and $-0.4 \mathrm{MPa}$, respectively) to reduce medium water potential. Lower water potentials that severely impaired germination and seedling growth were excluded from this experiment. MV (Syngenta, Wilmington, DE, U.S.A.) was added to MS media at a final concentration of 20 
$\mu \mathrm{M}$ after autoclaving; this herbicide accepts $\mathrm{e}^{-}$from photosystem I and transfers them to molecular oxygen. In this manner, destructive ROS are produced.

For all the experiments described, 25 seeds were planted in Magenta boxes. Each experiment included five replications (five Magenta boxes per treatment). The germination and seedling growth experiment was repeated once, but the gene expression study was repeated independently three times. Seeds were incubated at $25 \pm 1^{\circ} \mathrm{C}$ and $16 \mathrm{~h}$ of light. Germination percentages were measured after 14 days according to AOSA guidelines (AOSA 1999). At 21 days after the start of imbibitions, chlorophyll contents of the oldest true leaf of normal seedlings were measured with a precalibrated SPAD meter (Minolta, Ramsey, NJ, U.S.A.). Three seedlings per treatment per replication (total of 15 samples per treatment) were measured.

All normal seedlings in each Magenta box were harvested for shoot and root fresh weight determination, and then, all shoots and roots in each replicate were pooled and dried at $65^{\circ} \mathrm{C}$ for $48 \mathrm{~h}$ for the average dry weight determination.

To analyze gene expression in response to T22, four colonized or uncolonized seedlings per Magenta box were harvested 3 days after $50 \%$ of seeds germinated under control conditions. Roots and shoots were separated and were immediately immersed in liquid nitrogen. Plant tissue was ground separately in prechilled mortar and pestle with liquid nitrogen and were either immediately analyzed or were stored at $-80^{\circ} \mathrm{C}$.

Lowering water potential to $-0.4 \mathrm{MPa}$ was severe enough to decrease fresh weight of control seedlings by almost $50 \%$. Therefore, this level of stress was chosen for further studies to characterize antioxidant defense. To determine enzyme activity and concentration of antioxidants, five seedlings were harvested 3 and 10 days after $50 \%$ of seeds germinated from each Magenta box (under control or lowered water potential conditions), were pooled together, and were immediately immersed in liquid nitrogen. Roots and shoots were ground separately in prechilled mortar and pestle with liquid nitrogen and were either immediately analyzed or were stored at $-80^{\circ} \mathrm{C}$.

\section{Gene expression.}

The effect of T22 colonization on relative expression of genes encoding antioxidant enzymes was studied. Total RNA was extracted using RNeasy plant mini kit (Qiagen, Valencia, CA, U.S.A.) according to the manufacturer's instructions. DNase treatment was carried out using Turbo DNase (Applied Biosystems, Foster City, CA, U.S.A.) for $25 \mathrm{~min}$ at $37^{\circ} \mathrm{C}$. DNase-treated total RNA (1 $\mu \mathrm{g})$ was used for cDNA synthesis using SuperscriptTM III (Invitrogen, San Diego, CA, U.S.A.) according to manufacturer's instruction. Quantitative reverse transcription-polymerase chain reaction (PCR) analysis was performed with an iCycler iQ instrument using SYBR green mastermix (Applied Biosystem) and gene-specific primers described in Table 3. The PCR program consisted of an initial denaturation and $\mathrm{Taq}$ polymerase activation step of $5 \mathrm{~min}$ at $95^{\circ} \mathrm{C}$, followed by 40 cycles of $10 \mathrm{~s}$ at $95^{\circ} \mathrm{C}$ and $1 \mathrm{~min}$ at $60^{\circ} \mathrm{C}$. Full coding sequence of genes of interest was obtained from the National Center for Biotechnology Information database, and primers were designed using primer 3 in accordance with the criteria required for quantitative PCR primer design (Udvardi et al. 2008). The specificity of primers, lack of primer-dimer, and the absence of contaminating genomic DNA were verified, respectively, using amplicon dissociation curves, PCR in the absence of cDNA, and by PCR analysis of RNA samples before reverse transcription. The amplification efficiency of primers, calculated using LinReg (11.0), was $\geq 80 \%$, except for $\mathrm{GR}_{\mathrm{p}}, \mathrm{MDHAR}_{\mathrm{c}}, \mathrm{DHAR}_{\mathrm{p}}, \mathrm{APX}_{\mathrm{c}}, \mathrm{CZ}-\mathrm{SOD}_{\mathrm{c}}$, and $\mathrm{CZ}_{-} \mathrm{SOD}_{\mathrm{p}}$ with efficiencies $\geq 75 \%$. Actin was chosen as the reference gene due to its constitutive and stable expression (Perez-Bermudez et al. 2009; Vergne et al. 2007). Expression levels were normalized using actin as reference gene, and relative expressions of genes were calculated using the method of Ruijter and associates (2009).

\section{Measurement of antioxidants.}

The ASA ratio was determined using high-pressure liquid chromatography (HPLC) according to Davey and associates (2003), with modifications. Plant tissue was extracted in three volumes of $6 \%$ metaphosphoric acid containing $2 \mathrm{mM}$ EDTA and $1 \%$ polyvinylpolypyrrolidone. The extract was centrifuged for $12 \mathrm{~min}$ at $14,000 \mathrm{rpm}$ (Eppendorf, 5415C, Hamburg, Germany) at $5^{\circ} \mathrm{C}$ and the supernatant was used for analysis. A Hitachi LaChrom Elite HPLC system (Hitachi High Technologies America, Schaumberg, IL, U.S.A.) with an autosampler maintained at $6^{\circ} \mathrm{C}$ and a $120 \times 5 \mathrm{~mm}$ Synergi fusion column (Phenomenex U.S.A., Torrance, CA, U.S.A.) packed with $4 \mu \mathrm{m}$ of polar embedded $\mathrm{C} 18$ particles at $28^{\circ} \mathrm{C}$ were used. ASA was detected at $243 \mathrm{~nm}$ using a L-2420 UV-Vis detector (Hitachi High Technologies). The column was eluted with $1.0 \mathrm{ml}$ of 5 to $30 \%$ acetonitrile per minute of flow in a mobile phase consisting of $400 \mu \mathrm{l}$ of orthophosphoric acid ( $\mathrm{pH} 2.5)$ per liter. Analysis was completed in $12 \mathrm{~min}$. Samples were then reduced by dithiothreitol (Knöerzer et al. 1996) and were analyzed by HPLC to determine total ascorbate (ASA+DHA). ASA was deducted from total ascorbate to calculate the DHA. GSH and GSSG measurements were carried out according to spectrophotometric procedure described by Knöerzer (1996).

Table 3. Primers used for quantitative reverse transcriptase-polymerase chain reaction analysis of genes encoding antioxidant enzymes in tomato

\begin{tabular}{|c|c|c|c|c|}
\hline \multirow[b]{2}{*}{ Gene code } & \multirow[b]{2}{*}{ Encoded enzyme } & \multirow[b]{2}{*}{ GI number } & \multicolumn{2}{|c|}{ Primers } \\
\hline & & & Forward & Reverse \\
\hline $\mathrm{GR}_{\mathrm{p}}$ & Chloroplast glutathione reductase & 167047069 & ATAAAAATGCCGAGTTGCAG & GTTTACCATCCACATCCACTGT \\
\hline $\mathrm{GR}_{\mathrm{p}}$ & Cytosolic glutathione reductase & 220967701 & AACTGGATGGCACCAAGAT & СTCTTCCAAGCTCAAGGCTT \\
\hline $\mathrm{DHAR}_{\mathrm{c}}$ & Cytosolic dehydroascorbate reductase & 66475035 & TTCTGATGTCATTGTTGGGATTA & GCTCTTCGGAAATGAGACG \\
\hline DHAR $_{\mathrm{p}}$ & Chloproplast dehydroascorbate reductase & 66475037 & GAGGAGAAGTTCCCCAAACC & CGGAGTCTTTGCTTTTCAGG \\
\hline MDHAR $_{p}$ & $\begin{array}{l}\text { Chloroplast monodehydroascorbate } \\
\text { reductase }\end{array}$ & 110265125 & GGAATCTTTGCCATTGGAG & GGAATCTTTGCCATTGGAG \\
\hline $\mathrm{APX}_{\mathrm{c}}$ & Cytosolic ascorbate peroxidase 2 & 73761752 & ACTATGCTAAGGCTCACTTGACA & CTAACGATATCCAACAATTCCAG \\
\hline $\mathrm{APX}_{\mathrm{s}}$ & Stromal ascorbate peroxidase 7 & 74483952 & CTTGCGAATTTTCATCGACA & GTGCCTCCTCGAGTGGTTAG \\
\hline $\mathrm{AP}_{\mathrm{t}}$ & Thylakoid-bound ascorbate peroxidase 6 & 68300917 & CGAAAGATGGACCAGGAAG & AAGAACAGCATCTGTAGGCAAA \\
\hline CAT1 & Catalase 1 & 170397 & CTCAAACGCCTGTTATTTGTC & CGTGTCAGGGAACGACTTAG \\
\hline CAT2 & Catalase 2 & 5257184 & AGACAAGAACGCTTTATTCGTC & GCCTAGATGCAAGCTTTTGA \\
\hline F-SOD & Chloroplast Fe-superoxide dismutase & 33439119 & CTGGCTCTGCTACAATAACAGC & CCTGTGATACTTCCCCCAGT \\
\hline $\mathrm{CZn}-\mathrm{SOD}_{\mathrm{c}}$ & Cytosolic $\mathrm{Cu} / \mathrm{Zn}$-superoxide dismutase & 170511 & TGGTGATCTTGGTAACATCACA & TCCAATGATGGACTGTGGA \\
\hline CZ-SOD & Chloroplast $\mathrm{Cu} / \mathrm{Zn}$-superoxide dismutase & 19192 & AGGGTACAGTGGCTGTTGG & GTGAGTGGTCTTGCTCCGACT \\
\hline
\end{tabular}




\section{Enzyme activity measurement.}

Enzyme extraction and protein determination. Ground tissue was mixed with 10 vol of extraction buffer described by Knöerzer and associates (1996). Addition of $1 \mathrm{mM}$ ASA to the extraction buffer was necessary to avoid inactivation of APX (Amako and Asada 1992). The mixture was centrifuged at $14,000 \mathrm{rpm}$ (Eppendorf, 5415C) for $10 \mathrm{~min}$ at $5^{\circ} \mathrm{C}$, and the supernatant was used as the source of enzymes. Protein concentrations were determined according to Bradford (1976), with a standard curve prepared using bovine serum albumin. For CAT and SOD, enzyme activities were determined per gram of fresh weight.

Enzyme activity measurement. APX activity was assayed by decrease in absorbance at $290 \mathrm{~nm}$ due to oxidation of ASA (Knöerzer et al. 1996). MDAR activity was determined following the decrease in absorbance at $340 \mathrm{~nm}$ due to NADH oxidation as described by Hossain and associates (1984). DHAR activity was determined following method described by Hossain and Asada (1984) by the decrease in DHA concentration at $265 \mathrm{~nm}$. GR activity was determined by increase in absorbance at $412 \mathrm{~nm}$ according to Smith and associates (1989). SOD activity and CAT activities were measured per gram of fresh weight. SOD activity was determined by reduction in absorbance of light at $490 \mathrm{~nm}$ using an Oxiselect SOD activity assay kit (Cell Biolabs, San Diego, CA, U.S.A.) according to manufacturer's instruction. CAT activity was measured by reduction in absorbance of light at $520 \mathrm{~nm}$, using an OxiselectTM CAT activity assay kit (Cell Biolabs).

\section{Statistical analysis.}

All experiments were designed as factorial to test the effect of T22 ( \pm ) or water-deficit stress $( \pm)$ and their interactions on growth, chlorophyll content, and biochemical properties of seedlings. If the experiment was repeated in independent studies, the effect of repetition was also analyzed, and data were pooled whenever appropriate. Analysis of variance was performed using JMP 7 for Windows (SAS, Cary, NC, U.S.A.) statistical package.

\section{ACKNOWLEDGMENTS}

This work is part of the Ph.D. thesis of the first author, who was financially supported by an assistantship from Department of Horticultural Sciences, NYSAES, Cornell University. The authors would like to thank A. Dal Ri for his assistance with quantitative RT-PCR analysis and T. D. Spittler for his advice on HPLC procedure. We also acknowledge the United States Department of Agriculture Grape Germplasm Research Unit for making their HPLC system available. The technical assistance of A. Brooks and G. Knapton, which greatly facilitated this work, is also appreciated.

\section{LITERATURE CITED}

Amako, K., and Asada, K., 2000. Separate assays of ascorbate peroxidase and guaiacol peroxidase and of chloroplastic and cytosolic isozymes of ascorbate peroxidase. Photosynth. Res. 34:231.

AOSA. 2009. Seedling evaluation. Pages 110-115 in: Rules for Testing Seeds. Association of Official Seed Analysts, Washington, DC.

Apel, K., and Hirt, H. 2004. Reactive oxygen species: Metabolism, oxidative stress, and signal transduction. Annu. Rev. Plant Biol. 55:373-399.

Asada, K. 2000. The water-water cycle as alternative photon and electron sinks. Philos. Trans. R. Soc. London B Biol. Sci. 355:1419-1431.

Bae., H, Sicher, R. C., Kim, M. S., Kim, S. H., Strem, M. D., Melnick, R. L., and Bailey, B. A. 2009. The beneficial endophyte Trichoderma hamatum isolate DIS $219 \mathrm{~b}$ promotes growth and delays the onset of the drought response in Theobroma cacao. J. Exp. Bot. 60:3279-3295.

Baltruschat, H., Fodor, J., Harrach, B. D., Niemczy, K. E, Barna, B., Gullner, G., Janeczko, A., Kogel, K. H., Schaefer, P., Schwarczinger, I., Zuccaro, A., and Skoczowski, A. 2008. Salt tolerance of barley induced by the root endophyte Piriformospora indica is associated with a strong increase in antioxidants. New Phytol. 180:501-510.

Björkman, T., Blanchard, L. M., and Harman, G. E. 1998. Growth en- hancement of shrunken-2 (sh2) sweet corn by Trichoderma harzianum 1295-22: Effect of environmental stress. J. Am. Soc. Hortic. Sci. 123:35-40.

Bradford, M. M. 1976. A rapid and sensitive method for the quantitation of microgram quantities of protein utilizing the principle of protein dye binding. Anal. Biochem. 72:248-254.

Creissen, G., Firmin, J., Fryer, M., Kular, B., Leyland, N., Reynolds, H., Pastori, G., Wellburn, F., Baker, N., Wellburn, A., and Mullineaux, P. 1999. Elevated glutathione biosynthetic capacity in the chloroplasts of transgenic tobacco plants paradoxically causes increased oxidative stress. Plant Cell 11:1277-1292.

Davey, M. W., Dekempeneer, E., and Keulemans, J. 2003. Rocket-powered high-performance liquid chromatographic analysis of plant ascorbate and glutathione. Anal. Biochem. 316:74-81.

de Pinto, M. C., Francis, D., and De Gara, L. 1999. The redox state of the ascorbate-dehydroascorbate pair as a specific sensor of cell division in tobacco BY-2 cells. Protoplasma 209:90-97.

Foyer, C. H., Souriau, N., Perret, S., Lelandais, M., Kunert, K. J., Pruvost, C., and Jouanin, L. 1995. Overexpression of glutathione reductase but not glutathione synthetase leads to increases in antioxidant capacity and resistance to photoinhibition in poplar trees. Plant Physiol. 109:10471057.

Fujibe, T., Saji, H., Arakawa, K., Yabe, N., Takeuchi, Y., and Yamamoto, K. T. 2004. A methyl viologen-resistant mutant of Arabidopsis, which is allelic to ozone-sensitive rcd1, is tolerant to supplemental ultraviolet B irradiation. Plant Physiol. 134:275-285.

Harman, G. E. 2000. Myths and dogmas of biocontrol: Changes in perceptions derived from research on Trichoderma harzianum T-22. Plant Dis. 84:377-393.

Harman, G. E. 2011. Multifunctional fungal plant symbionts: New tools to enhance plant growth and productivity. New Phytol. 189:647-649.

Harman, G. E., Howell, C. R., Viterbo, A., Chet, I., and Lorito, M. 2004a. Trichoderma species-opportunistic, avirulent plant symbionts. Nat. Rev. Microbiol. 2:43-56.

Harman, G. E., Lorito, M., and Lynch, J. M. 2004b. Uses of Trichoderma spp. to alleviate or remediate soil and water pollution. Pages 313-330 in: Advances in Applied Microbiology. A. I. Laskin, J. W. Bennett, and G. M. Gadd, eds.

Hossain, M. A., and Asada, K. 1984. Purification of dehydro ascorbate reductase Ec-1.8.5.1 from spinach and its characterization as a thiol enzyme. Plant Cell Physiol. 25:85-92.

Hossain, M. A., Nakano, Y., Asada, K. 1984. Mono dehydro ascorbate reductase Ec-1.6.5.4 in spinach chloroplasts and its participation in regeneration of ascorbate for scavenging hydrogen per oxide. Plant Cell Physiol. 25:385-396.

Knöerzer, O. C., Durner, J., and Boeger, P. 1996. Alterations in the antioxidative system of suspension-cultured soybean cells (Glycine max) induced by oxidative stress. Physiol. Plant. 97:388-396.

Mastouri, F., and Harman, G. E. 2009. Beneficial microorganism Trichoderma harzianum induces tolerance to multiple environmental and physiological stresses during germination in seeds and seedlings. In: ISMPMI 2009 XIV Congress. Quebec, Canada

Mastouri, F., Björkman, T., and Harman, G. E. 2010. Seed treatment with Trichoderma harzianum alleviates biotic, abiotic, and physiological stresses in germinating seeds and seedlings. Phytopathology 100:12131221.

Miller, G., Suzuki, N., Rizhsky, L., Hegie, A., Koussevitzky, S., and Mittler, R. 2007. Double mutants deficient in cytosolic and thylakoid ascorbate peroxidase reveal a complex mode of interaction between reactive oxygen species, plant development, and response to abiotic stresses (1 W OA). Plant Physiol. 144:1777-1785.

Mittler, R. 2002. Oxidative stress, antioxidants and stress tolerance. Trends Plant Sci. 7:405-410.

Mittova, V., Volokita, M., Guy, M., and Tal, M. 2000a. Activities of SOD and the ascorbate-glutathione cycle enzymes in subcellular compartments in leaves and roots of the cultivated tomato and its wild salt-tolerant relative Lycopersicon pennellii. Physiol. Plant. 110:42-51.

Mittova, V., Volokita, M., Guy, M., and Tal, M. 2000b. Salt stress differentially affects lipid peroxidation and antioxidant system in leaf and root cell organelles of the cultivated tomato Lycopersicon esculentum and its wild salt-tolerant relative L. pennellii. Plant Physiol. Biochem. 38.

Noctor, G., and Foyer, C. H. 1998. Ascorbate and glutathione: Keeping active oxygen under control. Pages 249-279 in: Annual Review of Plant Physiology and Plant Molecular Biology. R. L. Jones, C. R. Somerville, and V. Walbot, eds.

Rizhsky, L., Liang, H., Shuman, J., Shulaev, V., Davletova, S., and Mittler, R. 2004. When defense pathways collide. The response of Arabidopsis to a combination of drought and heat stress. Plant Physiol. 134:16831696.

Rouster, J., Leah, R., Mundy, J., and Cameron-Mills, V. 1997. Identifica- 
tion of a methyl jasmonate-responsive region in the promoter of a lipoxygenase 1 gene expressed in barley grain. Plant J. 11:513-523.

Ruijter, J. M., Ramakers, C., Hoogaars, W. M. H., Karlen, Y., Bakker, O. van den Hoff, M. J. B., and Moorman, A. M. 2009. Amplification efficiency: Linking baseline and bias in the analysis of quantitative PCR data. Nucleic Acids Res. 37.

Sanchez-Rodriguez, E., Rubio-Wilhelmi, M., Cervilla, L. M., Blasco, B., Rios, J. J., Rosales, M. A., Romero, L., and Ruiz, J. M. 2010. Genotypic differences in some physiological parameters symptomatic for oxidative stress under moderate drought in tomato plants. Plant Sci. 178:30-40.

Shoresh, M., and Harman, G. E. 2008. The molecular basis of shoot responses of maize seedlings to Trichoderma harzianum T22 inoculation of the root: A proteomic approach. Plant Physiol. 147:2147-2163.

Shoresh, M., Yedidia, I., and Chet, I. 2005. Involvement of jasmonic acid/ethylene signaling pathway in the systemic resistance induced in cucumber by Trichoderma asperellum T203. Phytopathology 95:76-84.

Shoresh, M., Mastouri, F., and Harman, G. H. 2010. Induced systemic resistance and plant responses to fungal biocontrol agents. Annu. Rev. Phytopathol. 48:21-43.

Sivan, A., and Harman, G. E. 1991. Improved rhizosphere competence in a protoplast fusion progeny of Trichoderma harzianum. J. Gen. Microbiol. 137:23-30.

Smirnoff, N. 1993. Tansley Review No. 52: The role of active oxygen in the response of plants to water deficit and desiccation. New Phytol. 125:27-58.

Smith, I. K., Vierheller, T. L., and Thorne, C. A. 1989. Properties and functions of glutathione reductase in plants. Physiol. Plant. 77:449-456.
Udvardi, M. K., Czechowski, T., and Scheible, W. R. 2008. Eleven golden rules of quantitative RT-PCR. Plant Cell. 20:1736-1737.

Vergne, E., Ballini, E., Marques, S., Sidi Mammar, B., Droc, G., Gaillard, S., Bourt, S., DeRose, R., Tharreau, D., Notteghem, J.-L., Lebrun, M.H., and Morel, J.-B. 2007. Early and specific gene expression triggered by rice resistance gene $\mathrm{Pi} 33$ in response to infection by ACE1 avirulent blast fungus. New Phytol. 174:159-171.

Waller, F., Achatz, B., Baltruschat, H., Fodor, J., Becker, K., Fischer, M. Heier, T., Hueckelhoven, R., Neumann, C., von Wettstein, D., Franken, P., and Kogel, K. H. 2005. The endophytic fungus Piriformospora indica reprograms barley to salt-stress tolerance, disease resistance, and higher yield. Proc. Natl. Acad. Sci. U.S.A. 102:13386-13391.

Xiang, C., and Oliver, D. J. 1998. Glutathione metabolic genes coordinately respond to heavy metals and jasmonic acid in Arabidopsis thaliana. Plant Biol. 1998

Yedidia, I., Benhamou, N., and Chet, I. 1999. Induction of defense responses in cucumber plants (Cucumis sativus L.) by the biocontrol agent Trichoderma harzianum. Appl. Environ. Microbiol. 65:10611070.

Yildirim, E., Taylor, A. G., and Spittler, T. D. 2006. Ameliorative effects of biological treatments on growth of squash plants under salt stress. Sci. Hortic. (Amsterdam) 111:1-6.

\section{AUTHOR-RECOMMENDED INTERNET RESOURCE}

The National Center for Biotechnology Information Gene database: www.ncbi.nlm.nih.gov/sites/entrez?db=gene 